\title{
Regenerar \\ el tejido social de la esperanza
}

\author{
Gustavo Esteva
}

Universidad de la Tierra en Oaxaca, Oaxaca, México. Email: gustavoesteva@gmail.com

Resumen: Se presenta la hipótesis de que la mirada más allá de la modernidad puede descubrir la nueva sociedad que ha estado surgiendo en el vientre de la vieja. La insurrección de saberes subyugados e imaginaciones reprimidas, que caracteriza la transición, estaría definiendo una nueva perspectiva e interpretación del mundo, que serían expresión de la resistencia a la destrucción aún vinculada al viejo orden social y de los empeños de construcción del nuevo. comunidad

Palabras clave: Paradigma, convivialidad, interculturalidad, ámbitos de

\section{Regenerating the social tissue of hope}

Abstract: The hypothesis here presented is that a glance beyond modernity may discover the new society emerging in the womb of the old. The insurrection of subjugated knowledges and repressed imaginations, characterizing the transition, would be defining a new perspective and interpretation of the world, which would be expressions of the resistance to the destruction still associated with the old social order and the efforts of construction of the new.

Key words: paradigme, conviviality, interculturality, commons

\section{Regenerando o tecido social de esperança}

Resumo: Apresenta-se a hipótese de que um olhar além da modernidade pode descobrir a nova sociedade que vem surgindo no seio da velha. A insurreição do conhecimento subjugado e imaginações reprimidas, o que caracteriza a transição, seria a definição de uma nova perspectiva e interpretação do mundo, o que seria uma expressão de resistência à destruição ainda associado com a antiga ordem social e a construção do novo.

Palavras-chave: paradigma, convivência, interculturalidade, comunidade

$$
* * *
$$

En el punto de partida de este ensayo me debato entre dos posiciones diferentes: la de quienes intentan construir un nuevo paradigma social y la de quienes desconfían de esa empresa y consideran que para despertar de la pesadilla actual conviene aprender de la gente común, cuyos comportamientos se encontrarían ya más allá de las trampas e inviabilidades de la modernidad y la postmodernidad. 
De un lado, me gustaría seguir la línea de pensamiento que va de Wolfgang Dietrich a Bollier y Helfrich y conduce a la iniciativa de David Barkin.

Dietrich considera que la posmodernidad no es una época que sigue a la modernidad sino un aspecto de la condición moderna. La frustración por el fracaso de las promesas modernas y la desilusión con el proyecto social caracterizado por la física de Newton, el reduccionismo cartesiano, el estado-nación de Hobbes y el sistema capitalista profundizaron las dudas sobre ese paradigma que nacieron con la era moderna. Sería post-moderna una reflexión sobre la modernidad y un estado de pensamiento de varias generaciones que se han desprendido con dificultad de las verdades previas en que confiaban, sin haber encontrado un nuevo sistema unitario de referencia. Un número creciente de personas ha adquirido conciencia de la relatividad de aquellas verdades, que han perdido su carácter compulsivo, pero carece de un paradigma de semejante eficacia. Tal estado puede verse como anomia, simple pérdida de valores y orientación, o como anticipo de una percepción pluralista de la verdad.

Post-modernismo sería un método de conocimiento. Por muchos años, los científicos sociales reaccionaron ante la incertidumbre creada por la condición posmoderna con el argumento de que "bastarían dosis adicionales de los mismos remedios postulados por la modernidad para alcanzar el paraíso en la tierra”. Así lo plantearon “quienes abogaban por teorías del desarrollo, el progreso, la justicia, la democracia, la tecnología y en general los valores y estrategias universales... Argumentaron a favor del universalismo de los derechos humanos, el derecho internacional., el ajuste estructural, la buena gobernanza y la ética global (Dietrich 2011: 9)”. El posmodernismo trata de ir más lejos y puede verse como respuesta académica ante la carencia de las verdades que se consideraban certeras. Las ciencias sociales intentan elaborar nuevos conceptos que permitan interpretar la realidad social y hacer frente a la sensación general de inseguridad que se ha creado.

Bollier y Helfrich dan un paso más en esa misma dirección. Consideran que "se ha vuelto cada vez más claro que estamos suspendidos entre un viejo mundo que ya no funciona y otro nuevo que lucha por nacer. Rodeados por un orden arcaico de jerarquías centralizadas de un lado y de mercados predatorios por el otro, presidido por un estado comprometido con un desarrollo económico destructor del planeta, la gente está buscando alternativas en todas partes del mundo... No sólo quieren emanciparse de la pobreza y de las oportunidades que se desvanecen, sino de sistemas de gobierno que ya no les permiten tener voz y responsabilidad significativas" (Bollier y Helfrich 2012: xi). Los commons, los ámbitos de comunidad, serían un nuevo paradigma generador de opciones para escapar de la economía de mercado y crear modos de vida más completos.

David Barkin, por su parte, en el texto que preparó para convocar al coloquio "Hacia la construcción de un nuevo paradigma social”, mostró la 
urgencia de impulsar formas alternativas de organización ante los progresivos estragos sociales y ambientales de la sociedad centrada en el mercado. Subrayó que “en la vida universitaria e intelectual es imprescindible proponer nuevos paradigmas que trasciendan las disciplinas que respaldan el sistema actual, con su énfasis en el individualismo, la transformación de la naturaleza y las relaciones sociales en mercancías, la subyugación de todo al mercado y la centralidad de la propiedad privada. Entre los paradigmas heterodoxos de las ciencias sociales y en las prácticas ancestrales de las comunidades campesinas e indígenas, así como en sus formas actuales de organización y comportamiento, se hallan algunos principios para la construcción de nuevos modelos sociales. Analizarlos e incorporarlos a un conjunto teórico es la labor de los intelectuales comprometidos con las víctimas del sistema y con la consecución de un mundo mejor (Barkin 2011:1)”.

Comparto todas esas inquietudes. Sin embargo, desde que Kuhn renovó el uso de la palabra paradigma me provocó resistencia a su uso. Lo planteó de manera intrínsecamente circular: "Un paradigma es lo que los miembros de una comunidad científica comparten, y, recíprocamente, una comunidad científica consiste en hombres que comparten un paradigma (Kuhn 1971: 271)”. Según cuenta Kuhn, uno de los lectores de su famoso libro descubrió que había usado la palabra paradigma en 22 sentidos diferentes (Ibid: 279). Kuhn, empero, consideró que al eliminar los casos de mera inconsistencia estilística quedarían dos sentidos principales del término: el de "matriz disciplinal" y el de "ejemplo compartido". Éste último sentido, que según Kuhn es el aspecto más original y menos comprendido de su libro, se enmarca en el "conocimiento tácito” de Michael Polanyi (1958), que influyó considerablemente en las ideas de Kuhn. La descripción del procedimiento de construcción de los hechos científicos de Ludwig Fleck (1979) me ayudó a entender mi resistencia a la noción de paradigma de Kuhn. Iván Illich, a su vez, tanto en su vida como en su obra, tanto en su método de trabajo como en la manera de exponer los resultados de sus reflexiones, agudizó mis resistencias a la noción de paradigma, para preferir, a los enfoques científicos, la "investigación disciplinada, documentada y crítica (Illich 2008:332)”. Más que la esterilidad creciente del tipo de estudios que aún se llaman ciencia, es decir, su creciente incapacidad de entender lo que ocurre y acotar alternativas al desastre, me preocupa la naturaleza misma de los paradigmas como construcción científica, pues son fruto del acuerdo de los miembros de un grupo social, la llamada "comunidad científica”, que me inspira creciente desconfianza.

De otro lado, me atrae la continua invitación de Jean Robert, que comparte esa reticencia a trabajar con paradigmas. Nos exige preguntarnos por el suelo social de teorías e hipótesis: insiste en que adoptemos un punto de vista vinculado a un lugar único y concreto en un cosmos, al suelo que pisan los pies, en el que se entierran los ombligos, en el que montañas, ríos y bosques son hermanas y hermanos de quien formula una teoría, alguien que acaso recuerda también que theoría, para los griegos, era un festival, un espectáculo que podía ser de autores o de ideas y el theatron era el lugar de este espectáculo o festival intelectual (Robert 2010). Aún más me atrae 
su sugerencia de que la crisis actual puede llevarnos al pánico, si aceptamos que el capitalismo tendrá que hacer inevitablemente el pavoroso ajuste sistémico sin el cual no podría sobrevivir, o bien puede ser la oportunidad de tocar piso, formulando preguntas radicales sobre las ideas que se han tomado por verdades intocables por demasiado tiempo. Aún más que este enfoque, que todavía podría considerarse inmerso en una preocupación paradigmática de corte postmoderno, me interesa el Robert que desafía a la ciencia convencional y opta por la “investigación convivial”. En una carta personal que dirigió a Teodor Shanin, David Cayley y Bárbara Duden y compartió con algunos amigos, Jean recuerda que una gitana leyó en la mano de Iván Illich, siendo él muy joven, que descubriría una nueva ciencia. Es esto lo que habría realizado Illich, al desafiar el dominio de la "ciencia para la gente” y redescubrir y enriquecer la "ciencia por la gente”, que resultaría ser más scientia que toda la investigación financiable que pretende serlo (Illich 2008: 112 y sigs). En vez de importar conceptos de la ciencia convencional, acuñó los que serían las herramientas de la investigación convivial, fundada en la tecnología crítica. Con ellos creó nuevos espacios epistémicos, inaccesibles para la ciencia convencional.

Al seguir persistentemente este camino, me siento cada vez más inclinado a pensar que se produjo realmente la insurrección de los saberes subyugados que Foucault anticipaba en 1976: "saberes que estaban descalificados como saberes no conceptuales, como saberes insuficientemente elaborados: saberes ingenuos, saberes jerárquicamente inferiores, saberes por debajo del nivel del conocimiento o de la cientificidad exigidos” (Foucault 2002: 21). Esos saberes insurrectos inspiraron comportamientos específicos de la gente común en la hora de la crisis y configuraron las coaliciones de descontentos que caracterizan las formas de reaccionar ante el desastre en barrios y pueblos, en todas partes. $\mathrm{Y}$ ante la novedad de esos comportamientos, empezaron a tomar forma las anti-ciencias, las insurrecciones "contra los efectos del poder centralizadores que están ligados a la institución y al funcionamiento de un discurso científico organizado dentro de una sociedad como la nuestra”. Se empezaron a practicar, contra la tiranía de los saberes englobadores, distintas modalidades de genealogía: “el acoplamiento de los conocimientos eruditos y las memorias locales, acoplamiento que permite la constitución de un saber histórico de las luchas y la utilización de ese saber en las tácticas actuales”. (Ibid: 22)

Y así, llego al fin de este largo preámbulo para tratar de explicar la actitud que guía mi exploración, cuando empleo la tutoría de Iván Illich para constatar en la realidad componentes y rasgos de una nueva sociedad, más allá de la modernidad y la postmodernidad. La forja cotidianamente el empeño de personas comunes que en vez de un sistema unitario de referencia comparten percepciones pluralistas con las que están creando un mundo en que caben muchos mundos, como sugieren los zapatistas, y resisten la furia destructiva que aún se ejerce desde la era que termina. 


\section{La convivialidad}

Los “treinta años gloriosos” que según los analistas franceses se registraron al término de la Segunda Guerra Mundial, gracias a los acuerdos keynesianos construidos en el molde del New Deal, culminaron en los “años dorados" de 1960 a 1973. El "espíritu de los sesenta” se produjo en la tensión entre una corriente individualista y libertaria y otra solidaria, igualitaria y comunitaria y mostró un profundo rechazo a la soledad asociada con las relaciones sociales dominantes y la tecnificación. Fueron años de esperanza, en que se examinaron las cuestiones fundamentales con un vigor sin precedentes y se generó una ambiciosa agenda para la reconsideración de los valores culturales. "Todo fue puesto en cuestión: la familia, el trabajo, la educación, el éxito, la cordura, la locura, el cuidado de los niños, el amor, el urbanismo, la ciencia, la tecnología, el progreso, la riqueza... (Sbert 2009: 57)”. Deleuze y Guattari se refirieron a ese momento histórico estelar en términos inequívocos: "Se dieron momentos en los que parecía poderse ver de repente todo lo que una sociedad tenía de intolerable, al mismo tiempo que las posibilidades de otra realidad social (Weber 1998: 158)”.

Unos días antes del mayo parisino, en 1968, convocados por Aurelio Peccei, el economista y director de empresa italiano, se reunieron en Roma 30 individuos de diez países para discutir el predicamento actual y futuro de la humanidad. Continuaron sus reuniones en diversas partes del mundo. En una de ellas se creó el Club de Roma, cuyo informe de 1972 se hizo pronto famoso: pronosticó que a menos de tomar medidas radicales para limitar el crecimiento económico se produciría el colapso del sistema económico y social del mundo en unos 70 años (hacia 2020). Argumentaron vigorosamente por la necesidad de alcanzar un estado de equilibrio estable, dando por supuesto que se estaba cerca de llegar al límite de habitantes que el planeta podría soportar. Si bien reconocieron la necesidad de que los países menos avanzados y las poblaciones más pobres pudiesen mejorar su condición, pugnaron por cambios sustantivos en el comportamiento humano y el tejido social, en particular en relación con el ambiente, para evitar el desastre. El informe puso el mayor énfasis en la necesidad de limitar el crecimiento demográfico, pero sin descuidar la restricción en el crecimiento económico y en particular sobre su impacto en el ambiente. (Meadows y otros 1972)

En ese contexto moral, intelectual y político Iván Illich publicó los que llamaba sus "panfletos de Cuernavaca”. Formaban parte del despertar crítico que llevó al Club de Roma. Compartían la preocupación que éste manifestaba por moderar el crecimiento demográfico y la producción y consumo de bienes, pero llevaban el argumento mucho más lejos. Ante todo, señalaban que la expansión de los servicios haría más daño a la cultura que el causado por los bienes en el ambiente. La crítica radical de la escuela en La sociedad desescolarizada (Illich 2006), del transporte en Energía y equidad (Illich 2006) y del sistema de salud en Némesis médica (Illich 2006) ilustraron lo que denominó la contraproductividad propia de 
todas las instituciones modernas: el hecho de que, pasado cierto umbral, empiezan a producir lo contrario de lo que proponen.

En septiembre de 1971, Illich redactó con Valentina Borremans La necesidad de un techo común: el control social de la tecnología (Illich 2006). Presentó ahí la hipótesis de que sólo una sociedad que acepte la necesidad de escoger un techo común (límites máximos) de ciertas dimensiones técnicas en sus medios de producción tiene viabilidad y alternativas políticas. Entre 1971 y 1973 Illich discutió esta hipótesis con un grupo de latinoamericanos, en sus seminarios del CIDOC, y a partir de esas conversaciones publicó en 1973 el ensayo conocido como La convivencialidad (Illich 2006), que comienza con las siguientes palabras: "Durante estos próximos años intento trabajar en un epílogo a la era industrial. Quiero delinear el contorno de las mutaciones que afectan al lenguaje, al derecho, a los mitos y a los ritos, en esta época en que se condicionan los hombres y los productos. Quiero trazar un cuadro del ocaso del modo de producción industrial y de la metamorfosis de las profesiones que él engendra y alimenta (Illich 2006: 371)”.

Cien años antes Marx señaló que “si Rusia sigue marchando por el camino que viene recorriendo desde 1861, desperdiciará la más hermosa ocasión que la historia ha ofrecido jamás a un pueblo para esquivar todas las fatales vicisitudes del régimen capitalista (Marx 1946: 711).” Illich, por su parte, escribió: "Las dos terceras partes de la humanidad pueden aún evitar atravesar por la era industrial si eligen, desde ahora, un modo de producción basado en un equilibrio posindustrial, ese mismo contra el cual las naciones superindustrializadas se verán acorraladas por la amenaza del caos” (Ibidem). Se definieron así dos opciones que no se tomaron. Rusia desperdició su oportunidad histórica. Las naciones superindustrializadas se enfrentan ya a la amenaza del caos, mientras las demás continúan su loca carrera para alcanzarlas. Hace unos 20 años todavía se pensaba que China podría transformarse sin arrastrar al mundo al abismo: se movía en bicicleta. Hoy resurge el temor al "peligro amarillo" de que hablaba Napoleón: cien millones de automóviles limitan ya la circulación de 700 millones de bicicletas. En Beijing, donde antes contaban con seis carriles, las bicicletas se ven reducidas a uno. La perspectiva así abierta impone daños ambientales insoportables tanto para China como para el mundo entero. Las consecuencias sociales y políticas son aún más dañinas.

Además de realizar una rigurosa crítica radical del modo industrial de producción, capitalista o socialista, Illich acotó en La convivencialidad las condiciones de la reconstrucción convivial y anticipó las luchas que permitirían la inversión política necesaria y las formas en que reaccionaría la gente en la hora de la crisis - la hora actual. Sus ideas constituyen una guía útil para leer lo que está ocurriendo en el mundo. Mientras los gobiernos funcionan cada vez más como meros administradores de las corporaciones privadas, la gente común, por razones de estricta supervivencia o en nombre de antiguos ideales, ha estado reaccionando con vigor. Sus iniciativas se extienden y radicalizan cada vez más, hasta dar forma a una insu- 
rrección que resiste la marejada mortal que destruye por igual el ambiente y la cultura, y empieza la reconstrucción en términos muy semejantes a los anticipados por Illich.

La Real Academia Española admitió al fin la palabra convivialidad ${ }^{1}$. La considera un mexicanismo que sería sinónimo de camaradería. En inglés, conviviality es una condición festiva, un acompañamiento alegre y jovial. Convivio sigue siendo una palabra común en México, que se puede usar para un festejo formal en la oficina pero más bien alude a una reunión cálida de vecinos o amigos. En 1987, al visitar uno de los horrendos departamentitos que construyó el gobierno después del terremoto de 1985, en Tepito, una señora me dijo: "Sí, las paredes y los techos están mejor...pero aquí no hay convivialidad”. Resentía la pérdida del ambiente que había compartido en un típico patio de vecindad tepiteña, propicio a la convivialidad, imposible de alcanzar en la colección de encierros individualizantes que se construyeron como sustituto de lo que había destruido el terremoto.

Iván Illich estaba muy consciente de todas estas connotaciones de la palabra que empleó para articular su pensamiento. Si bien la tomó de BrillatSavarin, quien la acuñó en su Fisiología del gusto en 1825, la recogió en México y resonaba para él con el sentido que tiene entre nosotros. En todo caso, Illich cargó de nuevo sentido a la palabra, que desde él designa un nuevo marco de referencia, un nuevo tipo de sociedad. La convivialidad es ahora la libertad personal ejercida en una sociedad tecnológicamente madura que puede llamarse posindustrial. Debe distinguirse de la cohabitación fraternal y solidaria de comunidades intencionales y de otras iniciativas aisladas, como las de quienes se marginan poco a poco, con desgano y frustración, de la sociedad de consumo. Se refiere a una alternativa social que se hizo posible por la madurez plena de la industria. "Llamo sociedad convivial”, escribió Illich, “a aquella en que la herramienta moderna está al servicio de la persona integrada a la colectividad y no al servicio de un cuerpo de especialistas. Convivial es la sociedad en la que el hombre controla la herramienta”. Tras reconocer su deuda con Brillat-Savarin, Illich precisa "que en la acepción un poco novedosa que confiero al calificativo, convivial es la herramienta, no el hombre. Al hombre que encuentra su alegría y su equilibrio en el empleo de la herramienta convivial le llamo austero”. Austeridad, aclara, no implica aislamiento o reclusión, sino lo que funda la amistad; sería una virtud que sólo excluye los placeres que degradan la relación personal. "La austeridad forma parte de una virtud que es más frágil, que la supera y que la engloba: la alegría, la eutrapelia, la amistad (Illich 2006: 374)”.

Según Illich, "se debe saludar la crisis declarada de las instituciones dominantes como el amanecer de una liberación revolucionaria que nos emancipará de aquellas instituciones que mutilan la libertad elemental del ser humano... Esta crisis planetaria de las instituciones nos puede hacer llegar a un nuevo estado de conciencia que afecte a la naturaleza de la herramienta y a la acción a seguir, para que la mayoría tome el control... 
(Ídem: 385)”. De eso se trata. Hoy. Eso sería lo que están intentando millones de personas, alrededor del mundo.

Las corporaciones, pensaba Illich, pueden servirse del derecho y del sistema democrático para sentar su imperio. Consideraba que la democracia estadounidense podría sobrevivir a la victoria de Giap, que supo utilizar la maquinaria de guerra estadounidense para ganar su guerra en Vietnam, pero no podría sobrevivir al triunfo de las corporaciones. Advertía que la crisis total hace evidente que el Estado-Nación moderno no es sino un conglomerado de sociedades anónimas, donde cada constelación de gremios, corporaciones e instituciones trata de promover su propio producto y servir a sus propios intereses. "El conjunto produce bienestar...y el éxito se mide por el crecimiento del capital en todas estas sociedades. En su oportunidad, los partidos políticos reúnen a todos los accionistas para elegir un consejo de administración (Illich 2006:478/9)”. Como el estado se ha convertido en mero guardián de las instituciones dominantes, no puede ya desempeñar su función de gestión política. Cuando esto queda claro para la gente, en medio de la crisis generalizada, surge la oportunidad del cambio. "La pérdida de legitimidad del Estado, como sociedad por acciones, no invalida, sino que reafirma la necesidad de un procedimiento constitucional. La pérdida de credibilidad de los partidos, convertidos en facciones rivales de accionistas, no hace más que subrayar la importancia del recurso a los procedimientos contradictorios en política...La misma crisis general puede establecer, de forma duradera, un contrato social que abandone al despotismo tecnoburocrático y a la ortodoxia ideológica el poder de prescribir el bienestar, o bien puede ser la oportunidad para construir una sociedad convivial, en transformación continua dentro de un cuadro material que estaría definido por aboliciones racionales y políticas.” (Ibidem)

Illich estaba convencido de que los ideales socialistas no podrían hacerse realidad con las instituciones dominantes, sin sustituir la instrumentación industrial por herramientas conviviales. Y la reinstrumentación de la sociedad, por su parte, sólo podría realizarse adoptando los ideales socialistas de justicia. Al anticipar la crisis de las instituciones que daría lugar a una liberación revolucionaria y un nuevo estado de conciencia, Illich subrayaba que si las herramientas no se someten a un control político, "la cooperación de los burócratas del bienestar y de los burócratas de la ideología nos hará reventar de "felicidad". La libertad y la dignidad del ser humano seguirán degradándose, estableciendo una servidumbre sin precedentes del hombre a su herramienta. A la amenaza de un apocalipsis tecnocrático, yo opongo una sociedad convivial. La sociedad convivial descansará sobre contratos sociales que garanticen a cada uno el mayor y más libre acceso a las herramientas de la comunidad, con la condición de no lesionar una igual libertad de acceso a otro (Illich 2006: 385/6)”.

Cuarenta años después de esta formulación eso es lo que parece estar ocurriendo. La gente ha estado reaccionando ante una crisis que marca un cambio de época y una ruptura epistémica (Esteva 2009). Ante gobiernos en pánico por la movilización de la gente y estructuras de poder 
económico y político dispuestas a cualquier cosa para no perder su posición, millones de personas se han puesto en movimiento. Sus iniciativas toman ya la forma de una insurrección (Esteva 2012). Mantienen la resistencia, pero pasan a la desobediencia. Están en la protesta, pero se abren al rechazo radical. Cuestionan las decisiones cotidianas, los atropellos de cada día, la agresión interminable, todos los muertos y presos, todas las destrucciones ambientales, y al mismo tiempo desafían la legitimidad del sistema mismo, no sólo a sus operadores: les niegan su consentimiento y rechazan que la representación sea aún síntesis del consenso social. Las personas asumen cada vez más la obligación moral y social de negarse a obedecer a un aparato a final de cuentas anónimo y afirman su independencia de ese aparato, para dejar de ser esclavos de la herramienta, subsistemas de los sistemas. Reconocen la decadencia de la sociedad de consumo y bienestar, de un capitalismo organizativo y monopólico entretejido con el estado. Rechazan con creciente firmeza el despotismo democrático dominante bajo cuyo manto formal se disimula el imperialismo político, económico y técnico al que se somete cada vez más a todos, el que hace de toda promesa electoral un eslabón más de la cadena que aprisiona. Muestran y demuestran que la dominación de clase es ante todo dominación de la conciencia de la gente y de su confianza en sí misma - que se prolonga al reducir el cambio a sustitución de dirigentes. Poco a poco articulan los términos de una organización social basada en la energía personal, es decir, la energía que cada persona puede controlar, en la libertad regulada por los principios del derecho consuetudinario, en la rearticulación de la vieja triada: persona, herramienta y sociedad, y en el sustento de todo esto en tres pilares clásicos: amistad, esperanza y sorpresa.

\section{La opción ante la crisis y los ámbitos de comunidad}

Tras llegar a la cumbre todo camino es descenso, decía con sentimiento Juan José Consejo al reflexionar sobre lo ocurrido en la Cumbre de la Tierra de 1992, en Río (The Ecologist 1995: 9). Lo que parecía el triunfo final del ecologismo se convirtió en sonado fracaso. La suprema consagración de la moda Bruntland representó también el principio de su fin. Al adoptarse oficial y universalmente el evangelio del "desarrollo sostenible” se hicieron evidentes las insoportables contradicciones del término. Al mismo tiempo, en Río empezaron a manifestarse nuevas iniciativas que se estaban tomando en la base social y representaban una auténtica alternativa. El equipo de la revista inglesa The Ecologist recorrió el mundo para verlas de cerca y llegó a la conclusión de que su común denominador parecía encontrarse en la regeneración de los commons. Trató entonces de ofrecerles un marco histórico de referencia. Puso el acento en su cercamiento (the enclosure of the commons) como el mecanismo a través del cual se ejercieron todas las formas del colonialismo predatorio y se sentaron las bases de la sociedad industrial. Al redescubrir este hecho histórico, el equipo pudo mostrar cómo las fuerzas económicas mantienen aún ese impulso: en esa lógica podría encontrarse la clave para entender el proceso de destrucción de culturas y entornos que aún prosigue. Y en ese mismo movimiento intelectual, el equipo 
mostró por qué las iniciativas de la gente se han concentrado en detener ese cercamiento, cuando aún no ha concluido, o las orientan a recuperar y regenerar sus commons o a crear otros nuevos. The Ecologist produjo entonces un libro en que presentó la secuencia de acontecimientos históricos que nos llevaron a la situación actual, y un análisis documentado y riguroso de la manera en que la gente está tomando iniciativas, en todas partes del mundo, que les permiten tomar de nuevo en sus manos su destino (1995).

Existe una interesante controversia sobre la traducción del término commons: se está hablando de "comunes" y de "bienes comunes", lo mismo que de “ámbitos de comunidad”. No es una mera disputa semántica: se trata de definir un proyecto político. El cercado de los commons en Inglaterra es un hecho decisivo en la transición a la modernidad capitalista. ¿Cómo evitar que se pierda esa huella semántica al expresar la idea en español? La mayoría de los commons han sido desgarrados o destruidos en casi todas partes. Se han socavado las bases de su existencia. Quienes aún resisten los ataques y tratan de defenderlos se han estado uniendo a quienes buscan otras opciones de vida y creen encontrarlas en la regeneración de los commons: la resonancia histórica de la palabra estaría dando un sentido común a estos empeños muy diversos. Otros más intentan que se aplique la noción de commons y sus normas a condiciones del mundo natural que se comparten a escala planetaria: el aire, el agua, los bosques, y a dispositivos técnicos como el internet. Hablar de "comunes" o "bienes comunes", como se ha estado haciendo, no parece enteramente satisfactorio: la palabra "común” tiene cierta connotación negativa, inferior. Lo "común y corriente" llega a tomarse como grosería en el lenguaje ordinario y es siempre algo vulgar e inferior. Ocurre lo mismo en inglés. He optado por la expresión “ámbito de comunidad”, porque si bien se pierde en ella la huella histórica se logra retener la plenitud del sentido. Ámbito es el contorno o perímetro de un lugar, el espacio entre límites determinados; y comunidad es una palabra que retiene aún toda la fuerza de su historia y sentido, a pesar de sus usos equívocos en la formalización de comunidades que difícilmente lo son (como la de las naciones). Al mismo tiempo, me parece necesario destacar la necesidad de realizar una investigación histórica de enorme complejidad. Necesitamos estudiar y comparar, con todo rigor, las modalidades comunitarias que han existido en diversos tiempos y lugares. Del mismo modo que commons es un término genérico para una variedad de formas sociales existentes en Europa, y en particular en Inglaterra, antes de que la industrialización capitalista o socialista las convirtiera en recursos, comunidad o ámbitos de comunidad son expresiones formales a las que no puede reducirse la inmensa riqueza de las organizaciones sociales incluidas en esos términos. El ejido español no es idéntico al commons inglés, ni a las diversas organizaciones indígenas que los españoles etiquetaron con esa palabra, ni al ejido mexicano actual, inventado en la Constitución de 1917, hecho realidad por Cárdenas en la década de 1930 y reformulado o destruido a partir de $1992^{2}$. Menos aún caben en ella ciertas novedades contemporáneas (que no lo son tanto). La tertulia de los jueves, que tuvo lugar por 10 años en la década de 1980 en el Centro Cultural El Disparate en la ciudad de México, fue equivalente, pero no idéntica, al almuerzo de los 
miércoles en Berkeley, de la misma época, cuando Lee Swenson y sus amigos leían a Goodman, Nietzche o Huck Finn por el solo placer de hacerlo juntos y creativamente. Ambos eran ámbitos de comunidad, nuevos ámbitos de comunidad. Es necesario esclarecer lo que acerca y lo que aleja a estos dos grupos entre sí y con otras mil formas de existencia comunitaria, de antes y de ahora. Existen ya, pero resultan inútiles para el propósito, tipologías académicas más o menos pedantes. Se trata ahora de realizar un esfuerzo teórico de ordenamiento que muestre, en toda su riqueza, los rasgos diferenciales y en ocasiones convergentes de la variada experiencia humana de creación y mantenimiento de espacios de libertad. Hace falta saber todo lo posible sobre espacios que están fuera del umbral de lo privado pero no se definen como públicos. Son lo contrario a espacios de circulación, pero no consisten en meros refugios colectivos o cotos de caza. No son formas de propiedad o tenencia de la tierra. Son entresijos de hombres y mujeres en que el libre encuentro de maneras de hacer las cosas, de hablarlas y de vivirlas -arte, tecné- es expresión de una cultura al mismo tiempo que oportunidad de creación cultural. En esa exploración tendría que darse especial consideración a la hipótesis de Illich sobre la importancia del género en la configuración de esos espacios y en particular su sospecha de que el género está suspendido, pero no roto, en algunas comunidades contemporáneas (Illich 2008) ${ }^{3}$, así como a sus hipótesis sobre la construcción del individuo a partir de la creación del texto en el siglo XII (Ibid.) y sobre la amistad como clave para la creación de nuevos ámbitos de comunidad por los sujetos individualizados del mundo moderno. También necesitamos percibir sus límites (son ámbitos, contornos, perímetros) y en su caso sus cadenas, sus opresiones, sus camisas de fuerza. Esa visión histórica panorámica puede enriquecer nuestra percepción del presente, develando lo que ha sido opacado por la modernidad y des-cubriendo las opciones abiertas, como desafíos urgentes, en la hora de la muerte del desarrollo. ${ }^{4}$

Este género de reflexiones surgieron a partir de la crítica del desarrollo, que a mediados de los años ochenta llevó a poner de moda el término posdesarrollo. En América Latina se vivía la que se llamó "la década perdida para el desarrollo”. Para muchos de nosotros fue la década en que el mito del desarrollo se perdió. La ilusión que atrapó nuestra fantasía cuando el presidente Truman acuñó la palabra subdesarrollo el día en que tomó posesión, el 20 de enero de 1949, había quedado atrás. Truman prometió compartir los avances científicos y tecnológicos estadounidenses para que las áreas subdesarrolladas alcanzaran a las desarrolladas y así se cerrase la brecha entre los países ricos y los pobres; viviríamos así en mundo más justo e igualitario. En la década de 1980 estábamos muy conscientes de la manera en que ese sueño se había convertido en pesadilla. Treinta años antes Leonteiev había preparado la matriz estadística en que se planteaba que países como México o Brasil tardarían cuando más de 25 a 50 años en alcanzar a los desarrollados. El Banco Mundial informó en los años ochenta que se requerirían muchos años más; siglos, para algunos países. En 1960 los países ricos eran 20 veces más ricos que los pobres; 20 años después, gracias al desarrollo, eran 46 veces más ricos. La brecha se ha seguido 
abriendo. Aunque esta conciencia produjo rabia, frustración e individualismo en mucha gente, para buen número de nosotros fue la oportunidad de despertar. Se nos hizo evidente que no era necesario intentar la imposible carrera para alcanzar a los “desarrollados”, pues aún poseíamos nuestras propias definiciones de la buena vida. Era enteramente factible vivir conforme a ellas. Podíamos abandonar radicalmente la ilusión descabellada de adoptar el American way of life como norma universal para vivir bien, según sugería el catecismo del desarrollo. Ya no caeríamos en las trampas conceptuales que aparecieron más tarde con expresiones como desarrollo sustentable o desarrollo humano y mucho menos en las de la globalización, que apareció como nuevo emblema de la hegemonía estadounidense, para sustituir la maltrecha bandera del desarrollo al término de la guerra fría.

En esos años un grupo de amigos de Iván Illich nos reunimos periódicamente en torno a él para platicar sobre lo que significa estar más allá del desarrollo. Wolfgang Sachs se ocupó de editar el fruto de nuestras conversaciones en el Diccionario del desarrollo: una guía del conocimiento como poder (2001). Me tocó en ese libro escribir la entrada relativa a "desarrollo" y en mis conclusiones señalé entre otras cosas lo siguiente: los "marginales" están transformando su resistencia al desarrollo y a las formas económicas de vida en un empeño de liberación, que los lleva a reivindicar y regenerar sus ámbitos de comunidad o a crear otros nuevos; para ellos, desligarse de la lógica económica del mercado capitalista o del plan socialista se ha convertido en cuestión de supervivencia: están tratando de poner la esfera económica en el margen de sus vidas; la interacción en el seno de esos ámbitos de comunidad previene que la escasez (en el sentido económico del término) aparezca en ellos, lo que supone la redefinición de las necesidades.

Mi texto era un llamado a la acción para establecer controles políticos que protegieran los ámbitos de comunidad. Escribí entonces numerosos textos en torno al tema, que abordaban explícitamente la resistencia a la creación de escasez que se practica en la sociedad económica.

En esos mismos años, cuando The Ecologist encontró por todas partes la reivindicación de los ámbitos de comunidad, Elinor Ostrom decidió concentrarse en estudiarlos, lo que 20 años después le daría el Premio Nobel de Economía. En mis textos, yo intentaba mostrar que los pueblos indios de México, basados en lo que todavía tenían, material y espiritualmente, estaban abandonando la empresa imposible de recuperar, restaurar o reconstituir sus antiguos ámbitos de comunidad. Sin romper con la tradición, habían dejado de ver su pasado como destino y estaban tratando de llevar a la práctica sus sueños en ámbitos de comunidad nuevos o regenerados. Me parecía que trataban de avanzar hacia una forma de pluralismo radical, que podría dar lugar a la coexistencia armónica de pueblos culturalmente diferenciados. En vez de un pacto social entre individuos, la premisa del estado-nación moderno, estaban tratando de construir una sociedad en que mexicanos individualizados, occidentalizados, pudieran coexistir con personas $^{5}$ que viven en comunalidad ${ }^{6}$. No se trataba de reminiscencias del 
pasado o del imposible retorno a una condición pre-moderna, sino de creaciones estrictamente contemporáneas (Esteva 2000).

Desde los años ochenta estaba observando en México que campesinos, marginales urbanos e intelectuales desprofesionalizados se desarticulaban cada vez más de los mecanismos institucionales e intentaban impedir que sus eslabonamientos con ellos, aún indispensables, perturbaran excesivamente sus ideas, esperanzas y proyectos. Lo que estaba pasando entre las mayorías y entre algunas vanguardias disidentes, cuando trataban de retomar la vida entre las manos, parecía imposible para la sabiduría convencional e impensable para la minoría próspera, en las capas medias o altas de la sociedad. Pero esa transformación social profunda carecía de nombre. Empecé a sospechar que era una revolución de nuevo cuño y la llamé revolución de los ámbitos de comunidad ${ }^{7}$. Veía como realidad en germen, en mi mundo de pueblos indios, campesinos y marginales urbanos, lo que Iván Illich había identificado conceptualmente al referirse a la reapropiación de los bienes de los ámbitos de comunidad ${ }^{8}$

El acontecimiento decisivo de la década de 1990 fue el alzamiento zapatista del $1^{\circ}$ de enero de 1994 . Se trata de la iniciativa política más radical del mundo en el momento actual y quizá, también, la más importante. En la zona bajo control zapatista, en Chiapas, cientos de comunidades han hecho realidad modos contemporáneos de vida que desafían abiertamente al mercado y al Estado y avanzan con decisión más allá de la lógica del capital, más allá del capitalismo. Las comunidades zapatistas no aceptan recursos del Estado, ni siquiera para sus escuelas o centros de salud, y son muy cuidadosos en sus relaciones con el capital y el mercado, para mantener en el margen de sus vidas la esfera económica globalizada. La expresión ámbitos de comunidad describe con precisión sus modos de existencia, dentro de un régimen bien arraigado en diversas tradiciones pero enteramente contemporáneo, en lo que constituye una novedad sociológica y política. La insurrección zapatista generó la transición política en que aún se encuentra el país y sigue representando una opción política para millones de personas. (Esteva 1994, 2006a y 2006b). Su creación social y política corresponde claramente a la descripción de la sociedad convivial, ha que adopta los ideales socialistas pero en vez de intentar poner a su servicio las instituciones dominantes creadas en el capitalismo, en el modo industrial de producción, las invierte o disuelve. Demuestran en sus prácticas que la convivialidad no es hoy una utopía futurista, sino que forma parte de nuestro presente, aunque no nos hayamos dado cuenta. Tiene ya un lugar en el mundo - por eso no es utopía. Pero aún no lo reconocemos.

La profunda transformación social que está ocurriendo actualmente puede denominarse revolución de los nuevos ámbitos sociales -ampliando la expresión ámbitos de comunidad. Se trata de una revolución que va más allá del desarrollo y la globalización; margina y limita la sociedad económica, en sus formas capitalistas o socialistas, al rechazar la premisa de la escasez como base de la organización de la vida social; reivindica la comunalidad, frente al individualismo reinante; adopta nuevos horizontes 
políticos, más allá de los derechos humanos y el estado nación, sustentando en el pluralismo radical formas de organización social y política que permiten la coexistencia armónica de los diferentes; y emplea la democracia formal o representativa y la democracia participativa como formas de transición a la democracia radical, construida como reino de las libertades, tras expulsar a la economía del centro de la vida social e instalar en él de nuevo a la política y la ética.

Impulsan esta revolución quienes defendieron sus ámbitos de comunidad de colonialistas y desarrollistas que trataban de cercarlos y los están regenerando en términos contemporáneos, hasta convertirlos en una novedad sociológica y política. Para cercar a los cercadores, como han empezado a hacer, se alían con quienes buscan opciones de vida en nuevos ámbitos de comunidad y quienes intentan proteger ámbitos comunes como la ecología, el agua o los bosques.

Desde esta perspectiva, que distingue claramente entre ámbitos de comunidad regenerados, nuevos ámbitos de comunidad y ámbitos comunes (tres formas sociológicas alternativas al commons clásico anglosajón), sugiero que en vez de intentar el "manejo" ciudadano de los "comunes" en un mundo alternativo al neoliberal, nos propongamos la creación de un mundo en que quepan muchos mundos, en el cual cada una de aquellas formas de existencia social puedan florecer, en el seno de coaliciones ciudadanas de solidaridad y apoyo mutuo, que coexistan en armonía con otros modos de existencia social, con base en acuerdos sobre sus respectivos límites.

En las circunstancias actuales, es preciso impulsar la conmoción simultánea de ideologías e instituciones, como sostenía Foucault (2002); no basta cambiar la ideología, a fin de alterar el rumbo de los aparatos, o cambiar los aparatos mismos, sin modificar la ideología. Se trata de poner todas las herramientas, todos los sistemas, bajo control de la gente, como expresión de libertad. "El hombre deja de ser definible como tal cuando ya no es capaz de modelar sus propias necesidades mediante el empleo más o menos competente de herramientas que le proporcionó su cultura (Illich 2006: 516).

Es esto lo que está en curso. El mejor ejemplo es sin duda el de los zapatistas, que en la zona bajo su control han creado una nueva forma de vida y de gobierno que desborda claramente el marco dominante. Mantienen relaciones entre sí y con el entorno natural que dejan claramente atrás los patrones del capitalismo depredador y demuestran la viabilidad de una alternativa. Es un ejemplo único, por su profundidad y alcances, pero no se trata de un fenómeno aislado: en el mundo entero se multiplican las iniciativas que desgarran el tejido dominante y crean nuevas posibilidades.

En estos tiempos de miedo global, dice Eduardo Galeano, "quien no tiene miedo al hambre tiene miedo a la comida (2006)". Mil millones de personas pueden irse a la cama, cada día, con el estómago vacío; y las demás saben que a sus platos llegan productos que los enferman sin nutrirlos. Saben también que no pueden seguir esperando que las instituciones 
internacionales, los gobiernos y las corporaciones modifiquen el estado de cosas que ellos mismos han creado, a pesar de que se cuenta con todos los medios técnicos y económicos para evitar tal situación. Han comenzado a reaccionar. Cunde por todas partes el cultivo urbano de alimentos y se multiplican las iniciativas de regeneración rural. Vía Campesina, la organización de campesinos más grande de la historia, ha redefinido la soberanía alimentaria: se trata de definir por nosotros mismos lo que comemos...y de producirlo también nosotros mismos. Esta postura, que avanza día tras día en su materialización, corresponde claramente a los términos de una sociedad convivial.

Existen ejemplos claros en todas las esferas de la vida cotidiana y en todos los países. Se ha hecho enteramente evidente la contraproductividad de las instituciones modernas, incluyendo por supuesto a un régimen despótico de gobierno que aún se pretende democrático. La respuesta cada vez más organizada no está tomando la forma convencional, de corte partidario, y abandona la ilusión de que a golpes de urna será posible realizar los cambios que hacen falta. Las coaliciones de descontentos que Illich anticipó para el momento en que se demostrase que la sociedad industrial ha traspuesto sus límites se encuentran ya en marcha. Se están practicando ya, por la propia gente, las aboliciones racionales y políticas que se requieren en la construcción de una sociedad convivial.

En los centros autónomos de producción de conocimiento que se están multiplicando se construye paulatinamente una

\section{Agenda de reflexión y acción para la transición}

\section{El punto de partida} cionados.

Necesitamos consolidar y articular con claridad dos aspectos rela-

De un lado, establecer con claridad la naturaleza de las crisis actuales, que no son sólo una fase del ciclo económico, o sólo la crisis financiera y la ambiental y ni siquiera sólo la fase terminal del régimen capitalista de producción, sino crisis una de civilización, la cual implica crisis de la era moderna y de su paradigma; crisis del modo industrial de producción; crisis del modo de conocer (disciplinas, interdisciplina, ciencia...); crisis de los modos de gobernar (despotismo democrático, instrumentalismo de los aparatos de Estado, verticalismo corporativo y gremial...).

De otro lado, acotar la naturaleza de la búsqueda, que nacerá de la lucha misma, no de especulaciones e hipótesis sin suelo social y político; será plural...pues ha dejado de tener sentido una verdad única; no será una ruptura con el pasado, como la de la era moderna (el no a viejas ideologías y paradigmas no implica dejar de usar teorías que pueden arrojar luz sobre la realidad actual y prácticas y experiencias que anticipan la nueva era o la fortalecen; tampoco implican abandonar el recurso al precedente); expre- 
sará acuerdo (de cor, cordis, corazón) más que entendimiento; y dará cabida al empeño de intelectuales encarnados que pueden cumplir función de articulación y de documentación y formalización de experiencias.

\section{Principales líneas o campos de trabajo}

Buscaremos reformular y reivindicar la condición humana. El hombre ha muerto, como suponía Foucault. Esa invención del siglo XIX, que dio lugar al humanismo como perversión de todos los saberes, ha desaparecido. Es tiempo de volver a hombres y mujeres de carne y hueso, lo que implica: recuperar la carnalidad (reencantamiento del mundo, la no separación, no perder el sentido de los sentidos...); recuperar sentido de realidad (no tomar por realidades a las entidades abstractas, en cuyas burbujas la gente cree estar viviendo); recuperar la noción de género, para reinventar sus nuevas formas más allá de toda forma de sexismo; recuperar sentido de proporción (la cuestión de la escala, la teoría de la morfología social...) y replantear la cuestión del sujeto.

Reivindicaremos el pluriverso, para crear un mundo en que quepan muchos mundos, como han sugerido los zapatistas. Para ello, es preciso reconocer la radical otredad del otro; el imperativo intercultural; la calidad, condiciones y desafíos del diálogo intercultural; la posibilidad del pluralismo radical, más allá del universalismo y el relativismo; y la afirmación política de las identidades culturales y su negación filosófica y sociológica como configuración de mismidades.

Fortaleceremos y reivindicaremos formas políticas propias, más allá del despotismo democrático y el estado-nación; más allá de la premisa de la escasez como fundamento de la organización social; más allá de la transformación “desde arriba” y el paradigma leninista, como afirmación de autonomías múltiples y como clave de la armonía de los diferentes (juntos pero no revueltos), por la ley y el orden creados y operados por la propia gente, más allá del poder cosificado (lo que se tiene o no, lo que puede distribuirse), con nuevas formas de lucha, que reconocen el conflicto y recurren al precedente (más allá de las marchas, las masas, etc.), reinstalando en el centro de la vida social la política y la ética y fundando la organización social en la amistad, la esperanza y la sorpresa.

Afirmaremos y reivindicaremos nuevas miradas, que reconozcan la importancia de la lengua (palabras como símbolos, la lucha por los conceptos) y el papel de la poesía en la transición de una era a la otra y como intuición radical, abandonando la pretensión de ver la sociedad en conjunto y reconociendo múltiples formas de conocer, de semejante rango y aplicación diversa.

Por último, reivindicaremos y reformularemos nuevas tecnologías que desafían centralismos y autoritarismos y expresan sujetos colectivos/ comunitarios que se autoconstituyen. 


\section{Notas}

${ }^{1}$ Ignoro la razón de que los traductores del libro de Illich hayan elegido la voz convivencialidad en vez de convivialidad. Aunque pertenecen a la misma familia de significados, tienen diversas connotaciones. Tanto en francés como en inglés Illich usó convivialidad, que era una palabra de amplio uso en México, en barrios y comunidades, aunque la Real Academia Española no la haya incorporado a su diccionario hasta hace pocos años. Creo que hay buenas razones para preferir convivialidad. Según Jean Pierre Corbeau (Wikipedia) Brillat Savarin creó el neologismo para designar "el placer de vivir juntos, de buscar los equilibrios necesarios para establecer una buena comunicación, un intercambio sincero y amigable alrededor de una mesa. La convivialidad corresponde al proceso por el cual se desarrolla y asume el papel de convidado, siempre asociado a la compartencia alimentaria, superponiéndose a la comensalidad”. Sería ese el sustrato en el que Illich construyó los nuevos significados de la palabra, un sustrato mucho más amplio y rico que la mera convivencia - el simple acto de vivir en compañía, de habitar bajo el mismo techo. En las citas de Illich que empleo en el texto sustituyo la palabra convivencialidad que usaron los traductores por convivialidad.

2 "Ejido" viene de exitus, salida. En la España del siglo XVI se empleaba para referirse a las tierras ubicadas "a la salida" de los pueblos, cuyo uso en común por los campesinos era semejante al de los commons en Inglaterra. Los españoles emplearon esa palabra para referirse a formas de tenencia y uso de la tierra que encontraron en el mundo indígena y les parecieron semejantes a las del ejido español. Pero los españoles no tenían una palabra ni una forma de percepción que les permitiera captar el sentido y características de la variedad de modos de vida comunal que habían encontrado. Los habían reducido entonces a un común denominador, considerándolos semejantes a los ejidos españoles. En la lucha por recuperar sus territorios y regímenes, los pueblos indios se vieron obligados a emplear el término, que la Corona incluyó en los documentos en los cuales empezó a dejar constancia de su reconocimiento formal de esos ámbitos. Al final del periodo colonial los españoles se referían ya a las "repúblicas de indios", no a los ejidos, reconociendo al fin la diferencia y admitiendo que eran complejos regímenes de vida y gobierno y no sólo de tenencia de la tierra o de formas comunales de uso de la misma, equivalentes a los ejidos españoles o al commons inglés. A principios del siglo XX, cuando esos pueblos indios y sus aliados mestizos tomaron en sus manos la revolución iniciada por Madero, adoptaron la bandera de la "reconstitución de los ejidos", que para ellos implicaba retomar su camino en sus propios espacios de libertad. Los ejidos españoles eran comparables al commons anglosajón: pertenecían a la misma especie. Pero los regímenes comunales de los pueblos del continente americano eran algo enteramente distinto.

${ }^{3}$ Illich empieza El género vernáculo_con las siguientes palabras: "Defino la ruptura con el pasado, descrita por otros como la transición al modo capitalista de producción, como el paso de la égida del género al régimen del sexo” (Illich 2008: 181). En el libro elabora con claridad las condiciones históricas en que el ámbito físico y cultural de una comunidad puede estar determinado por su forma específica de relaciones de género.

${ }^{4}$ El libro del equipo de The Ecologist contiene buenas pistas sobre la exploración histórica que hace falta y la vitalidad actual de los commons. El libro de Peter Linebaugh (2008) es una contribución de enorme importancia para esa investigación.

${ }^{5}$ Persona significa máscara en latín y griego. Aludía habitualmente a la de los actores en el teatro. Se aplica apropiadamente a quienes, bajo la máscara de un individuo biológico, 
son nudos de redes de relaciones reales (Panikkar 1995).

${ }^{6}$ La conmemoración de los 500 años abrió un inmenso debate en que los pueblos indios mostraron con vigor sorprendente su capacidad de afirmarse en su propio camino, distinto al marcado para todos, dentro de las realidades contemporáneas. El debate fue particularmente intenso en Oaxaca, el único estado de México en que la mayoría de la población es india y en donde conviven 16 pueblos diferentes. Dos intelectuales indios, Jaime Martínez Luna, zapoteco, y Floriberto Díaz, mixe, acuñaron en esas circunstancias, en forma independiente, la palabra comunalidad para poder compartir con otros su experiencia de vida en comunidad. El debate mostraba la decisión de los pueblos indios de mantener y actualizar sus modos de vida y gobierno, de corte comunal, pasando de la resistencia a la liberación en su empeño de transformación y abandonando toda forma de individualismo. Para referirme a sus regímenes en abierto proceso de regeneración empecé a emplear la expresión ámbitos de comunalidad. Parecía evidente que existía un vínculo entre ellos y los commons del mundo anglosajón, pero también que existía una gran distancia entre la tradición indígena y la de los herederos de la Magna Carta.

${ }^{7}$ Esta nueva revolución, estrictamente contemporánea, se inscribiría en la tradición de las revoluciones vernáculas a las que se refiere Teodor Shanin (1990).

8 "Reapropiación de los bienes de los ámbitos de comunidad. El término communaux es antiguo en francés, y lo es también en otras lenguas: commons, en inglés, Almende o Gemeinheit en alemán...gli usi civici en italiano. Los ámbitos de comunidad eran las tierras a las que todos los habitantes de una comunidad tenían derechos de uso adquiridos, no para extraer una ganancia monetaria sino para asegurar la subsistencia familiar. Los ámbitos de comunidad son esas partes del medio ambiente cuyo usufructo está garantizado por la ley de la costumbre, respecto a las cuales ésta impone formas específicas de respeto comunitario... Aquellos que luchan por la preservación de la biosfera y aquellos que rechazando un estilo de vida caracterizado por el monopolio de mercancías sobre las actividades intentan recobrar poco a poco la capacidad de vivir fuera del régimen mercantil de la escasez, convergen actualmente en una alianza nueva en el seno de la cual todas las corrientes tienden a la recuperación y aumento de los ámbitos de comunidad. Esta realidad social que está en vías de surgir y converger es llamada por André Gorz el “archipiélago de la convivencialidad”. El instrumento principal para la cartografía de este nuevo mundo es la obra de Valentina Borremans, Guide to Convivial Tools, Special Report núm. 13, Library Journal, Nueva York,1980, guía razonada que registra más de mil bibliografías, catálogos, periódicos, etc. (Illich 2008: 196)”.

\section{Bibliografía}

Barkin, David (2011), “Hacia la construcción de un nuevo paradigma social”. http://laisumedu.org/pdf/barkin.pdf (consultado 23/10/2012)

Bollier, David y Silke Hekfrich (2012), The Wealth of the Commons: A World Beyond Market \& State, The Commons Strategies Group, Levellers Press, Amherst, MA

Dietrich, W., Echavarría, J., Esteva, G., Ingruber, D. y Koppensteiner, N. (Ed.) (2011), The Palgrave International Handbook of Peace Studies: A 
Cultural Perspective, Palgrave Macmillan, Houndmills, Basingtoke, Hampshire.

Esteva, Gustavo (1994ª), Crónica del fin de una era. Editorial Posada, México.

Ídem (1998), “The Revolution of the New Commons”, en: C. Cook y J.D.Lindau (Eds.), Aboriginal Rights and Self-Government, McGill-Queen’s University Press, Montreal.

Ídem (2006a), Celebración del Zapatismo, edición ampliada y revisada, Ediciones ¡Basta!, Oaxaca.

Ídem (2006b), La Otra Campaña, la APPO y la izquierda. Znet.

http://www.zmag.org/content/showarticle.cfm?SectionID= 59\&ItemID=11652 (consultado 31/10/12)

Ídem (2009), “La crisis como esperanza”, Bajo el volcán, 8, 14.

Ídem (2012), Antistasis: L’insurrezione in corso, Asterios Editore, Trieste.

Fleck, Ludwik (1979), Genesis and Development of a Scientifict Fact, University of Chicago Press, Chicago.

Foucault, Michel (2002), Defender la sociedad, Fondo de Cultura Económica, México.

Galeano Eduardo (2006), http://yorecomiendo.wordpress.com/2006/11/08/ el-miedo-global-de-eduardo-galeanola-gran-orquesta-republicana/ (consultado 30/10/2012)

Kuhn, Thomas S. (1971), La estructura de las revoluciones científicas, Fondo de Cultura Económica, México.

Illich, Iván (2006), Obras reunidas, Vol. I, Fondo de Cultura Económica, México.

Ídem (2008), Obras reunidas, Vol. II, Fondo de Cultura Económica, México.

Linebaugh, Peter (2008), The Magna Carta Manifesto: The Struggle to Reclaim Liberties \& Commons for All, University of California Press, Berkeley.

Marx, Carlos (1959), El Capital, Vol. I, Fondo de Cultura Económica, México.

Meadows, Donella y otros (1972), The Limits to Growth, New American Library, Nueva York. En español: ebookbrowse.com/los-limites-del-crecimiento-pdf-. (consultado 24/10/2012) 
Panikkar, Raimón (1995), Invisible Harmony, Fortress Press, Minneapolis.

Polanyi, Michael (1958), Personal Knowledge; Towards a Post-Critical Philosophy, University of Chicago Press, Chicago.

Robert, Jean (2008), Carta personal a Teodor Shanin, David Cayley y Bárbara Duden, con copia al autor.

Ídem (2010), De Aguascalientes, caracoles y sociedad civil: de teorías y de práctica, ponencia presentada en el I Seminario Internacional de Reflexión y Análisis “Planeta Tierra, movimientos antisistémicos”, realizado en el Centro Indígena de Capacitación Integral/Universidad de la Tierra en Chiapas del 30 de diciembre de 2009 al 2 de enero de 2010.

Sachs, Wolfgang (Ed.) (2001), Diccionario del desarrollo: una guía del conocimiento como poder, Galileo Ediciones, México.

Sbert, José María (2009), Epimeteo, Iván Illich y el sendero de la sabiduría, Ediciones sin nombre, México.

Shanin, Teodor (1990), El Marx tardío y la vía rusa: Marx y la periferia del capitalismo, Editorial Revolución, Madrid.

Steger, Hanns-Albert (1984) “Conviviality” in: Hanns-Albert Steger (Ed.), Alternatives in Education, Wilhelm Fink Verlag München, Nuremberg.

The Ecologist (1995), El nuevo ecologismo: Manifiesto de los ámbitos de comunidad, Posada, México.

Weber, Henri (1998), Que reste-t-il de mai 68? Essai sur les intreprétations des “événements”, Éditions du Seuil, París.

Recibido: 15.10 .2012

Aceptado: 07.11.2012 